\title{
Cervical Spine Biomechanics: A Review of the Literature
}

\author{
Donald F. Huelke and Guy S. Nusholtz \\ University of Michigan, Department of Anatomy and Cell Biology, and the Biosciences Division \\ of the Transportation Research Institute, Ann Arbor, Michigan, U.S.A.
}

\begin{abstract}
Summary: This article reviews the many clinical and laboratory investigative research reports on the frequency, causes, and biomechanics of human cervical spine impact injuries and tolerances. Neck injury mechanisms have been hypothesized from clinically observed cervical spine injuries without laboratory verification. However, many of the laboratory experiments used static loading techniques of cervical spine segments. Only recently have dynamic impact studies been conducted. Results indicate that crown-of-head impacts can routinely produce compression of the neck with extension or flexion motion. However, the two-dimensional (midsagittal) movement of the head bowing into the chest does not routinely produce flexion/compression type damage to the cervical spine. Flexion/compression damage to the cervical spine can be produced by prepositioning the subject so that upon impact, a three-dimensional motion of the head and neck occurs. Future laboratory research is needed to determine the forces and impact directions required to produce the various known fracture types and dislocations for a clear, accurate description of the cervical spine impact dynamics. Key Words: Literature review-Biomechanics-Impact tolerances-Future research.
\end{abstract}

There has been a plethora of articles in the clinical literature related to cervical spine injuries. Most have detailed individual clinical case histories, suggested treatment plans, and some have described cervical spine injuries with little information on the specific biomechanics of the injury mechanism. There have been a number of clinical reports that focused on the classification and descriptions of cervical spine fractures and dislocations, with some providing hypotheses on the mechanism of injury $(3,4,15,16,36,46,53,69,71-$ $73,84,91,96,98,99,105)$. From the clinical literature, about a dozen different types of neck fractures or fracture/dislocations have been described, the most frequent being of the flexion/compression or the extension/compression type. Most of the clinical

Address correspondence and reprint requests to Dr. D. F. Huelke at University of Michigan, Medical School, Department of Anatomy, Medical Sciences II Building, Room 3738, Ann Arbor, MI 48109, U.S.A. literature has not been based on the results of laboratory tests, but has primarily relied on unproven and untested hypotheses gathered from clinical cases. Many laboratory tests on individual cervical vertebrae or cervical segments were conducted statistically and not in a dynamic environment. Studies of neck fractures and fracture/dislocation without head impact have also been reported $(\mathbf{1 8}, 45)$. Sances et al. $(87)$ presented a biomechanics review that included epidemiology, overview of fracture types, a review of some clinical literature, as well as biomaterials testing results, including ligaments, spinal cord injury tolerances, cord evoked potentials, animal studies, thoracolumbar injury data, and tolerances of nonvertebral structures, including extremity bones and the skull. To date, however, there have been few experimental studies to determine human cervical spine tolerances to impact. This article gives an indication of the importance of cervical spine injuries and provides some direction for future research. Only recently 
have laboratory experiments been conducted with cadavers in an impact environment, thus providing data with which to begin to clarify spinal impact biodynamics.

\section{OVERVIEW}

The magnitude of the cervical spine injury problem is unknown. However, the study by Krause et al. (61) indicates that annually there are approximately 11,200 spinal cord injuries, with 5,350 deaths before or during hospitalization. These are probably conservative estimates due to the low autopsy rates for untreated fatalities in the United States, especially of those in motor vehicle crashes. In the National Crash Severity Study (38) file, autopsy information is not available in the majority of fatal cases.

No data are available on the frequency of cervical-spinal cord injuries. The number of fractures or dislocations of the cervical spine without cord injury would probably far exceed the number with spinal cord injury. Estimates are that approximately 6,000 passenger car occupants die each year, principally of neck fracture or dislocation and cord damage (47). About 2,000 of these deaths are associated with ejection from the car, an event easily prevented by lap-shoulder belt usage (44). An estimate of surviving cervical-spinal cord injured passenger car occupants is 500-650 annually $(47,48,62)$. Many of the cervical-spinal cord injuries are sustained in automobile crashes, and articles on the subject of cervical spine injuries relative to the automobile crash environment are available $(2,11,17,29,42,43,47-49,56,57,64,73,76,77,97)$. As a significant number of cervical injuries are sustained in motor vehicle crashes, King (58) has emphasized the need for biomechanical studies by stating, "Intelligent design of safety features in vehicles for the protection of occupants is necessarily based on knowledge and understanding of human biodynamic response to impact." Only by accurate laboratory testing can data be obtained on impact biodynamics so that meaningful information can be provided to the designer of vehicle safety components in an attempt to reduce cervical spine injuries.

\section{LITERATURE REVIEW}

\section{General}

Snyder (92) reviewed the early human impact tolerance literature for both whole body acceleration and regional impact. His review indicated that in 1970 , well over 200 papers concerning neck injury had been published, and yet the precise definition, nature, measurement, and diagnosis of neck injury and treatment are still a subject of controversy. The most extensive compilation of articles on the cervical spine was published by Van Eck et al. (103), and their work remains an important reference manual on cervical injuries and range of motion. For a review of the literature on animal experiments, mathematical models, and the biodynamic response of the spine, King's paper (58) is noteworthy. Biomechanical properties of the neck in lateral hyperflexion were presented by Synder el al. (93); Melvin (74) briefly summarized cervical injury mechanisms; and King (59) reported on neck tolerance to indirect impact. Goldsmith (33) has reviewed head and neck injuries and their prevention. The voluntary cervical range of motion and the strength of cervical muscles were measured by Foust et al. (30).

Barnes (4) indicated that the first recorded description of paraplegia from cervical spine injury is found in the Edwin Smith Papyrus, written some 4,000 years ago. For practical reasons, two studies were conducted on the forces required to cause cervical spine fractures in judicial hanging, for at public hangings the "audience" did not want to observe decapitation or a suffocation death. One of the earliest attempts to calculate the forces on the neck in a dynamic event was presented in 1866 by the Reverend Samuel Haughton, M.D. (37), a fellow of the Trinity College in Dublin. He not only chronicled the biblical history of hanging, but he determined, through mathematical calculations, the drop height to properly cause cervical injury in judicial hanging. Later, James Berry (9), the Public Executioner of Great Britain, likewise presented his formula for determining the appropriate drop height to adequately hang an individual without decapitation.

\section{Clinical Studies}

Clinical reports on postulated mechanisms for head/neck motions required to produce cervical spine injuries were summarized by Babcock (3), Braakman and Penning (15), Kattan (55), and Portnoy et al. (84). Although at least a dozen different types of fractures of the cervical spine have been described, the four most prominently discussed in the clinical literature are flexion and extension, with either compression or tension (Fig. 
1). It is widely assumed that the classic flexion/ compression fracture combines significant forward bending of the head with a marked downward force. This is thought to cause the typical compression of the anterior cervical body with, at times, associated injuries of the posterior ligaments, spinous processes, or laminae (Fig. 2). Flexion, with tension applied to the neck, is thought to cause disruption of the posterior elements, separation of the articular facets, and dislocation. In general, the clinical literature has always described the need for the neck to be in a hyperflexed or hyperextended position, in association with compression or tension, without laboratory experimental verification.

Injury mechanisms in sports have also been considered $(88,100)$. Torg et al. $(101,102)$ and Frankel and Burstein (31) indicated that many cervical spine injuries in football are due to extreme axial loading on the straightened cervical spine and that the straight cervical spine, when axially loaded, acts as a segmented column. They noted that when the neck is in partial flexion, the cervical spine is in fact straightened. In a straightened spine, the load is transmitted axially to the thorax and greater force at the crown of the head can be generated than the normal lordotic cervical curve will allow. When the spine is not straight (normal standing position) or the load is off-axis, the load-carrying capacity is reduced and the column tends to buckle.
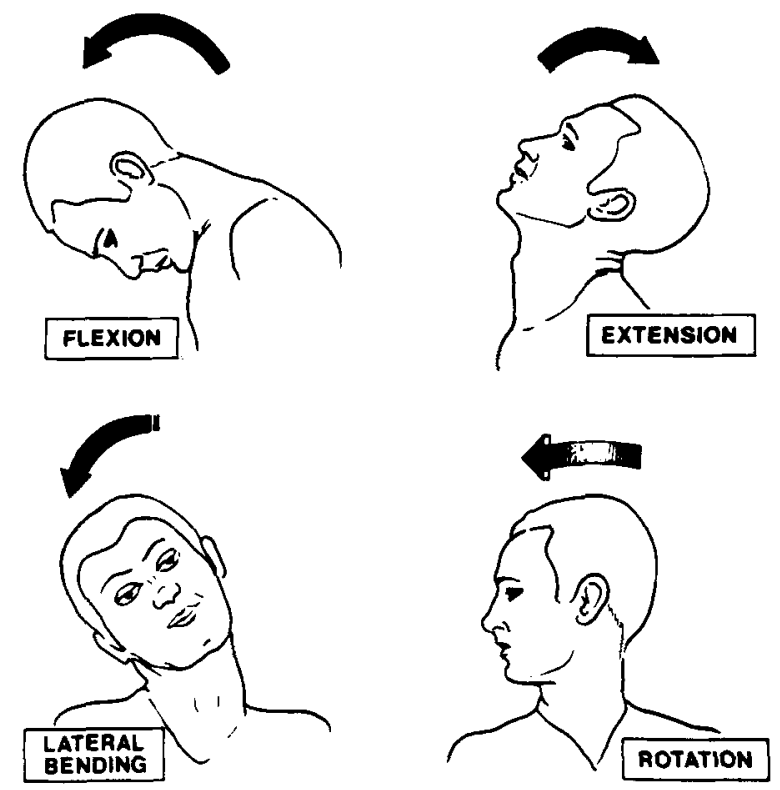

FIG. 1. Varieties of pure head-neck motion, extremes of which have been claimed to cause cervical fracture or fracture/dislocations.

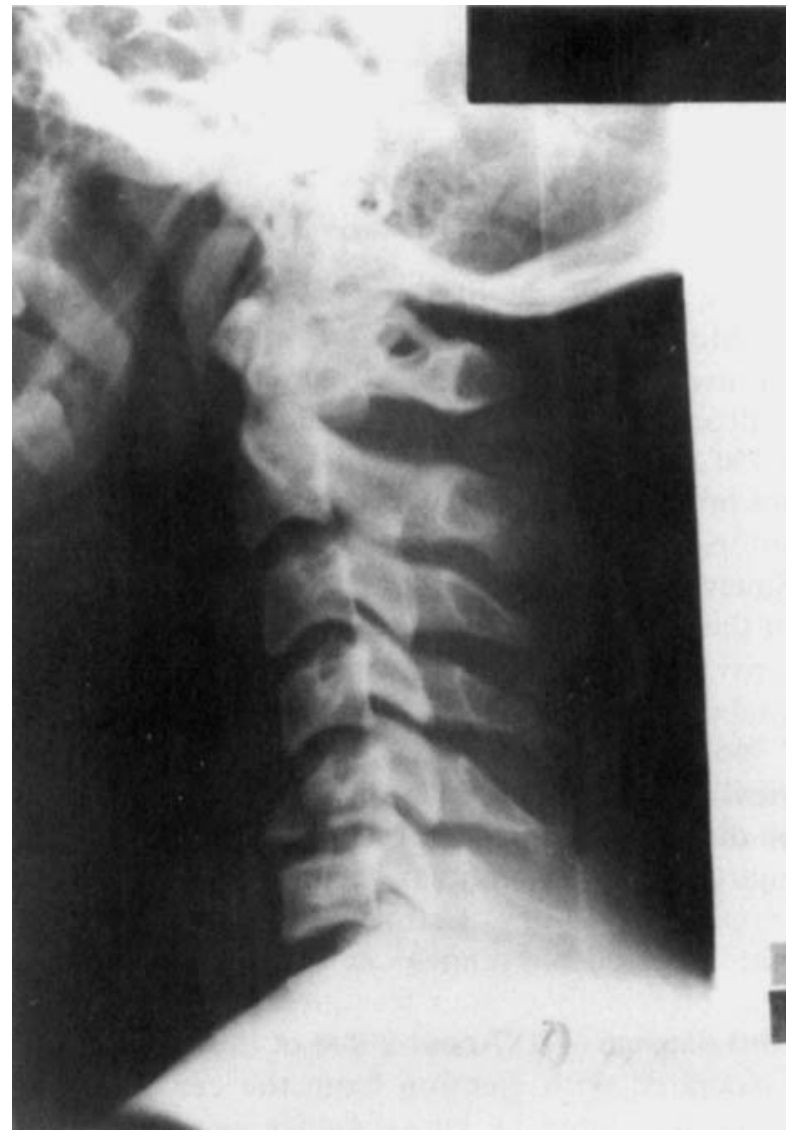

FIG. 2. Classic flexion-compression fracture at C5. Experimentally, this injury can best be produced by nonaxial prepositioning of the head (slightly flexed), neck (laterally bent and rotated), relative to the torso.

The biomechanical studies of Culver et al. (21) and Nusholtz et al. (79) support these findings.

\section{Neck Fracture Tolerances from Case Analysis and Human Volunteers}

Mertz and Patrick (75) estimated human tolerance values for the cervical spine subject to indirect loading. Based on human volunteer testing and on cadaver sled tests, they found that the resultant bending moment about the occipital condyles was an excellent indicator of neck strength. They also defined head and neck response and tolerance levels for both extension and flexion. Based on cadaver test data, their suggested tolerance level for the resultant bending moment is $190 \mathrm{~N}-\mathrm{m}(140 \mathrm{ft}-\mathrm{lb})$ in flexion and $57 \mathrm{~N}-\mathrm{m}(42 \mathrm{ft}-\mathrm{lb})$ in extension. These are considered lower bounds, as similar bending moments cause no discernable ligamentous damage in cadavers. Other studies on the neck response of human volunteers, usually at the subinjury level, have been conducted $(22,23,25,32,65,89,104)$. 
McElhaney et al. (67) studied neck injuries related to diving. Conducting diving studies using volunteers, they determined diver velocity at various water depths. They also reviewed a series of 41 cases of cervical injury from diving off the edge of a pool into water less than $4 \mathrm{ft}(1.2 \mathrm{~m})$ in depth and determined head impact velocities of $10.2-21.5 \mathrm{ft} / \mathrm{s}(3.1-6.6 \mathrm{~m} / \mathrm{s})$. In another 16 cases, springboard diving into water less than $3.5 \mathrm{ft}(1.1$ $\mathrm{m})$ in depth produced calculated head impact velocities of $12.5-26 \mathrm{ft} / \mathrm{s}(3.8-7.9 \mathrm{~m} / \mathrm{s})$. Nine injuries from water slides into water of less than $3.5 \mathrm{ft}$ (1.1 $m$ ) in depth were associated with head impact velocities of $11.7-16.2 \mathrm{ft} / \mathrm{s}(3.6-5.0 \mathrm{~m} / \mathrm{s})$. They concluded that the tolerable velocities for neck loading in flexion/compression with a free-moving individual are less than $10.2 \mathrm{ft} / \mathrm{s}(3.1 \mathrm{~m} / \mathrm{s}$ ). (An object dropped from $1.6 \mathrm{ft}$ or $0.5 \mathrm{~m}$ will reach this velocity at contact with the ground.)

\section{CERVICAL SPINE SEGMENT TESTS}

Mechanisms of fracture and dislocation studies of the cervical spine have been conducted using cervical spine segments $(5,28,64,68,81,94)$. Bauze and Ardran (5) used 14 unembalmed cadavers, removing a vertebral segment from the basiocciput to the T5 level. Stabilizing the lower segment by inserting a rod into the spinal canal, the specimens were loaded from above. Such loading produced extension at the atlanto-axial joint and the upper cervical spine and, at the upper end of the rod, at the midcervical level, vertebral compression, flexion, and horizontal shear forces. Such forces were found at the junction of the fixed (lower) and movable (upper) parts. The maximum load was $1,324 \mathrm{~N}(300 \mathrm{lb})$ prior to dislocation. The highest vertical load recorded was $1,422 \mathrm{~N}(320 \mathrm{lb})$. Fielding et al. (28) studied the proximal cervical spine in 10 young unembalmed cadavers. They removed the $\mathrm{C} 1, \mathrm{C} 2$, and the basiocciput as a unit, fixed the $\mathrm{C} 2$ vertebra, and applied an anterior load to the $\mathrm{C} 1$ vertebra via instrumented sling. The force applied to the sling produced an anterior load to $\mathrm{Cl}$ vertebra. The force applied to the sling pulled $\mathrm{C} 1$ and the basiocciput anteriorally in a slightly flexed position, with $\mathrm{C} 2$ remaining stationary. Results indicate that the transverse ligament of the dens ruptured at a mean force of $824 \mathrm{~N}(185 \mathrm{lb})$ (range $118-1,765 \mathrm{~N}$ ) for 20 specimens. In addition, they determined that the force required to fracture the C2 odontoid process alone was between $686-1,765$
N (155-397 lb). This failure load was never less than the force required to cause failure of all ligaments supporting the odontoid process. Following rupture of the transverse ligament, a mean force of $706 \mathrm{~N}(159 \mathrm{lb})$ (range 196-1,177 N) was necessary to produce a $12-\mathrm{mm}$ displacement of $\mathrm{Cl}$, a value thought to be sufficient to cause major spinal cord injury. Spence et al. (94) reproduced the tests of Fielding et al. (28) with modifications and demonstrated a good agreement with the Fielding et al. data.

Panjabi et al. (81) used cervical segments from eight unembalmed cadaver specimens, taking, for example, C2-C3, C4-C5, C6-C7. The distal vertebrae were held firm, and $25 \%$ of the cadaver body weight was applied, causing flexion or extension. The individual ligaments holding the vertebrae together were cut, either from anterior to posterior or posterior to anterior, and with each section, the amount of vertebral displacement was measured. They found that anterior ligaments provided structural stability in extension and posterior ligaments provided it in flexion.

McElhaney et al. (68) loaded unembalmed human cervical spines in compression and demonstrated most of the common fractures seen clinically. They noted that alignment of the load was significant, as $\pm 1 \mathrm{~cm}$ forward or backward, right or left, made a significant difference in the outcome (sic, in the type of fracture). It is reasonable to assume that in the cervical spine segment tests reported above, multiaxial loading will occur, i.e., compression, transverse shear, and bending. However, in these experiments, the assumption is that the principal loading is uniaxial in the S-I direction. No tests have been conducted on cervical spine segments where multiaxial loadings were purposely planned or analyzed.

\section{Intact Cadaver Tests}

Intact human cadavers have been subjected to a variety of impact situations in attempts to simulate frontal, rear-end, or rollover types of car crash situations (Fig. 3). Lange (63) used human cadavers on an acceleration sled and determined, from several front and rear-end collisions, the relative rotation between the head and torso due to the impact event. The torque exerted at the cervical spine was also estimated. He concluded that (a) both the relative rotation between the head and the torso and the torque exerted at the cervical spine significantly 


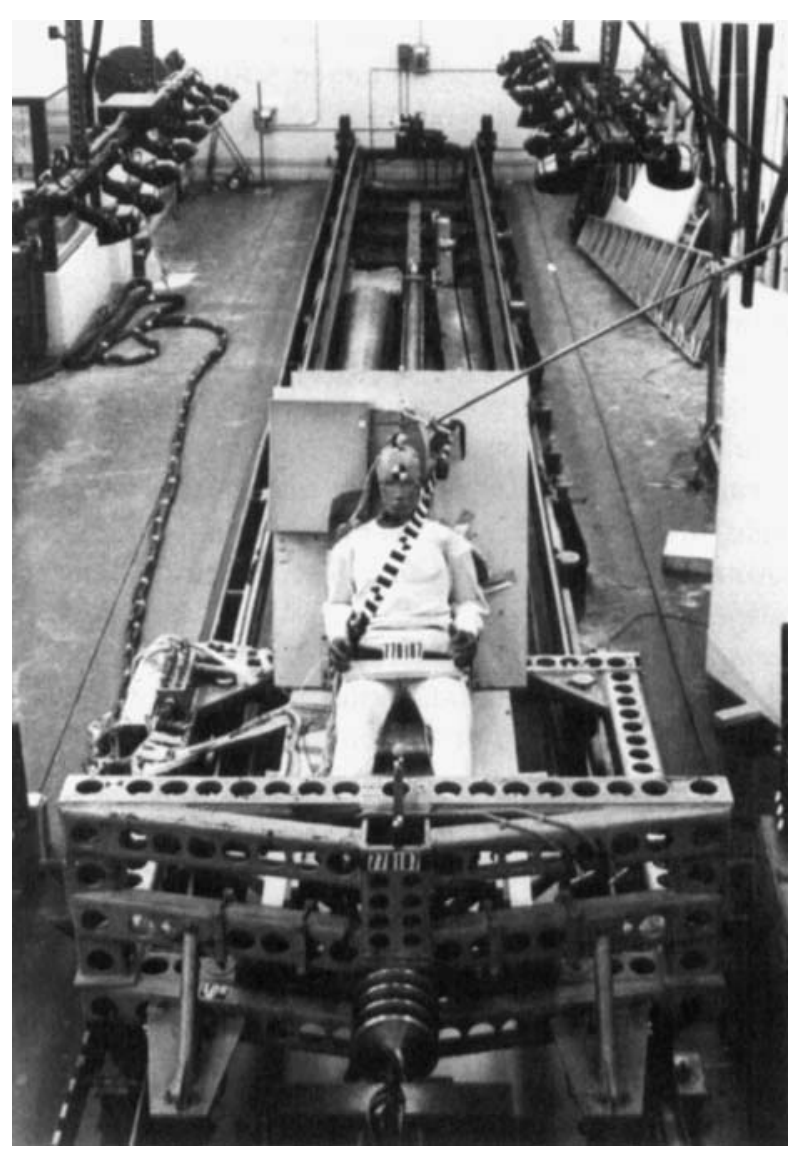

FIG. 3. Impact test facility that can be used for human tolerance research.

affected the type and severity of damage to the cervical spine; (b) the magnitudes of rotation and torque in turn depend on the amount and the direction of impact on the support offered to the body by a backrest, headrest, or steering wheel; and (c) rotation and torque also depend on the type of safety belts used, on their plasticity, and on the snugness or slack with which they are worn.

Cromack and Zipperman (20) studied five cadavers wearing lap-shoulder belts in a 1972 fullsized car on an acceleration sled. The change in velocity $(\Delta V)$ was $30 \mathrm{mph}(48 \mathrm{kmph})$, with $21-g$ peak deceleration. Two specimens exhibited no neck injury at autopsy. One specimen sustained a fracture of $\mathrm{C} 4$ with a crushed spinal cord, and another two specimens sustained fractures of the $C 5$ vertebra.

Using 16 unembalmed cadavers wearing lapshoulder belts on an impact sled, Patrick and Levine (82) found neck fractures in 3 of 4 cases at 40 mph $(64 \mathrm{kmph})$ with a 40 -in $(1.0 \mathrm{~m})$ stopping distance. Along with injuries to other body regions, there was one case with a fracture of the body of $\mathrm{C} 6$ in these simulated collisions. Another case exhibited bilateral fracture of the lateral process of the atlas. A third case demonstrated severe separation between $\mathrm{C} 5$ and $\mathrm{C} 6$.

Levine et al. (66) subjected 10 lap-belted unembalmed cadavers to frontal impacts at $29-40 \mathrm{mph}$ (46-64 kmph), with peak decelerations of $13-18 g$. Knee braces simulated quadriceps action and prevented displacement of the lower torso beneath the lap belt. Four cervical injuries were noted, two at the highest impact speed and two at the lower speeds.

Hu et al. (41) studied cadaver impacts in rear-end sled tests with deflecting and nondeflecting seatbacks, simulating that of a car at rest being impacted in the rear by a second car of equal weight traveling at $32 \mathrm{mph}(51 \mathrm{kmph})$. All three cadavers tested with a deflecting seatback suffered severe neck injuries, whereas two of the three cadavers on rigid seatbacks suffered similar injuries. The small data set and the "mixture" of male and female cadavers with a large spread of size, weight, etc., does not allow for statistical conclusions.

Got et al. (35) found bone and soft tissue injuries in 7 of 13 unembalmed cadavers sustaining forehead impacts with hyperextension of the head greater than $65^{\circ}$ Similar injuries were found in 2 of 22 cadavers subjected to lateral head impact with $55^{\circ}-89^{\circ}$ of head inclination. The specific type of neck damage was not described.

Clemens and Burow (19) used the upper torso of unembalmed cadavers between the ages of 50 and 90 years. The test speed was $8 \mathrm{mph}(13 \mathrm{kmph})$ in both frontal and rear impact simulations. In 19 tests, there was an average 15-g deceleration. They indicated that the neck can tolerate forces of $130-150 \mathrm{lb}(579-667 \mathrm{~N})$. The injuries included tears of the ligaments, discs, and fractures of vertebrae, as well as tears of the anterior and posterior longitudinal ligaments (45\% being at the C5-C6 level). In rear-end impact experiments, the 15 tests were conducted at about $19 \mathrm{kmph}(13-16 \mathrm{~g})$. There was disc damage in $90 \%$ of their specimens, torn anterior longitudinal ligaments in $80 \%$, tears of the joint capsules in $40 \%$, with fractures of the bones in $30 \%$, tears of the ligamentum flava in $10 \%$, and posterior longitudinal ligament tears in $10 \%$. These injuries were mainly at the $\mathrm{C} 5 / \mathrm{C} 6$ or the $\mathrm{C} 6 / \mathrm{C} 7$ level.

Jones et al. (52) studied injuries resulting from simulated experimental rear impact at relatively low speeds. Six cadavers were used, five being 
male (52-64 years old). Average sled deceleration was $17.8 \mathrm{~g}$ (range 14.5-19.9). Of the six cadavers, five had injuries to the cervical area in the $\mathrm{C} 5-\mathrm{C} 7$ region (for example, subluxation, compression fractures, disc ruptures).

Cheng et al. (18) exposed unembalmed cadavers to anterior-posterior acceleration by applying a frontal load to the chest using a predeployed air bag. In three of six experiments, several neck injuries were sustained. High neck loads were encountered in this mode of impact. The proposed resultant neck fracture load was $6.2 \mathrm{kN}(1,400 \mathrm{lb})$.

Culver et al. (21) studied 11 unembalmed cadavers in which the crown of the head was loaded in the superior-inferior direction. A 10-ky piston with a $15-\mathrm{cm}$ diameter, round, padded surface was placed in contact with the crown of the head. Loading at the cervical spine was obtained by accelerating the piston. Peak forces up to $5.7 \mathrm{kN}$ $(1,280 \mathrm{lb})$ produced cervical vertebral spinous process fractures via compressive arching of the spine.

Hodgson and Thomas (39) also reported on superior-inferior impacts to the protected (helmeted) head, indicating that static loading can be a useful predictor of the failure site under dynamic conditions. They found that the extent to which the head was gripped by the impact surface (to allow or restrict motion at the atlanto-occipital junction), the impact location, and the alignment of the impact force all influenced the injury site and the maximum strain value, as measured by strain gauges mounted on the cervical vertebrae.

Kallieris et al. (54) reported on studies of spinal column injuries in unrestrained unembalmed cadavers (male and female, 14-66 years old) in simulated frontal crashes at $49-51 \mathrm{kmph}$ ( $31 \mathrm{mph}$ ). They used a car body shell with bucket seats, decelerated by a deforming metal strap. There were 23 lapbelted tests and 10 tests in the air bag, knee-bar series. In these simulated severe collisions, the typical cervical spine injury occurred between $\mathrm{C} 3$ and T4 and was a tear-drop fracture of the body associated with disc ruptures and tears of the ligamentum flavum. More than one site of injury was reported in some specimens. Hardly ever $(20 \%)$ was the injury associated with vertebral body compression. Head-neck motion studies showed these to be flexion-related injuries. In the air bag tests, the injury characteristically included a laceration of the anterior longitudinal ligament or laceration of the anterior part of a disc. In the more severe injury cases, there were fractures (tears) of the upper or lower adjacent vertical body. These injuries were described as due to "retroflexion," i.e., extension.

\section{Current Biomechanical Studies}

With the modern tools of high-speed photography and x-rays, triaxial accelerometers, and improved analytical techniques, a more accurate determination of spinal dynamics under impact conditions can be made. Recently, Nusholtz et al. (79) attempted to reproduce the "flexion-type" of cervical spine damage in 12 unembalmed human cadavers impacted under conditions hypothesized to cause such injuries in the clinical literature (Fig. 4). A $56-\mathrm{kg}$ free-moving pendulum impact was used to provide cranial impacts to the vertex of the head of a prone subject. Their findings indicate that:

(a) The classical clinical description of head bowing the the chest is not necessary for "flexion-type" injuries. Cervical spine damage of the flexion-type was observed to occur with some extension head motion, and "extension-type" damage occurred with maximum head flexion motion.

(b) The initial orientation of the spine relative to the impact axis was a critical factor influencing the type of kinematic response and damage produced.

(c) Energy-absorbing materials were effective methods of reducing peak impact force, but did not necessarily reduce the amount of energy transferred to the head, neck, and torso, or the cervical damage produced.

Although in some tests, flexion/compression damage was observed in the upper thoracic spine, only 1 of the 12 cadavers sustained this type of damage in the cervical spine. Usually, extension/ compression-type damage was observed (Fig. 5).

Recently, Alem et al (1) presented data from superior-inferior crown impacts to unembalmed cadavers, via a $10-\mathrm{kg}$ free-flying mass. Some important findings resulted from this study:

(a) Peak force was not found to be a useful predictor of cervical spine injury, because forces as low as $3 \mathrm{kN}$ produced cervical spine damage and forces up to $16 \mathrm{kN}$ produced no cervical spine damage. Tests above $16 \mathrm{kN}$ (forces as high as $35 \mathrm{kN}$ ) showed no spinal injury, but skull damage was noted in the basilar area or was localized beneath the impact site. 


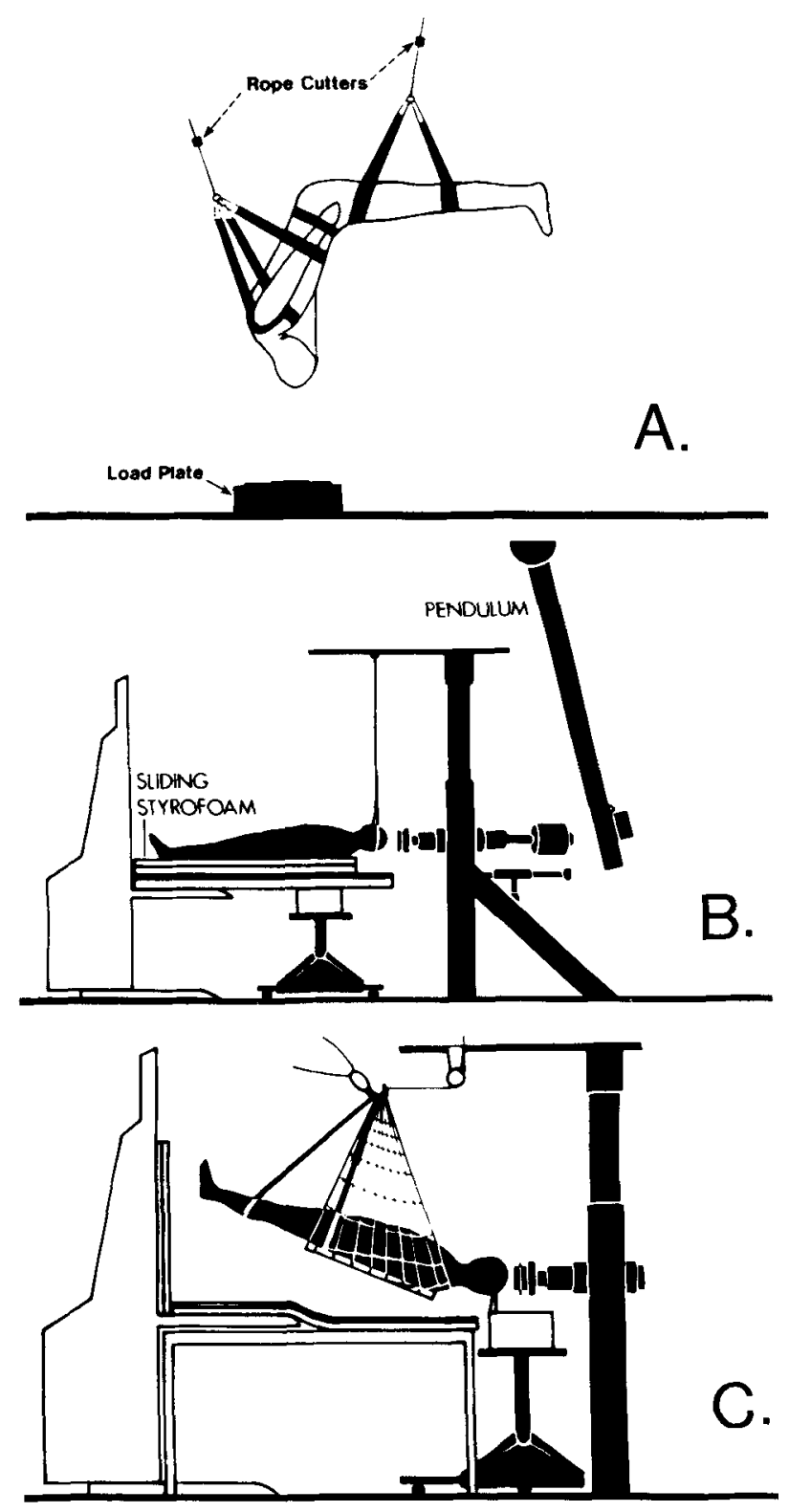

FIG. 4. Variety of preimpact positions of cadaver specimen used in determining the various parameters involved in the injury mechanisms to the cervical spine.

(b) A useful predictor of injury may be the impulse (integral of the force over time) of the impact and the maximum head velocity.

Most recently, Nusholtz et al. (80) studied the effects of head/neck/torso configuration and impact conditions on the kinematic response and damage for unembalmed cadavers following crown impacts (Fig. 6). In these head drop tests from about $1 \mathrm{~m}$ (body inverted), they concluded:

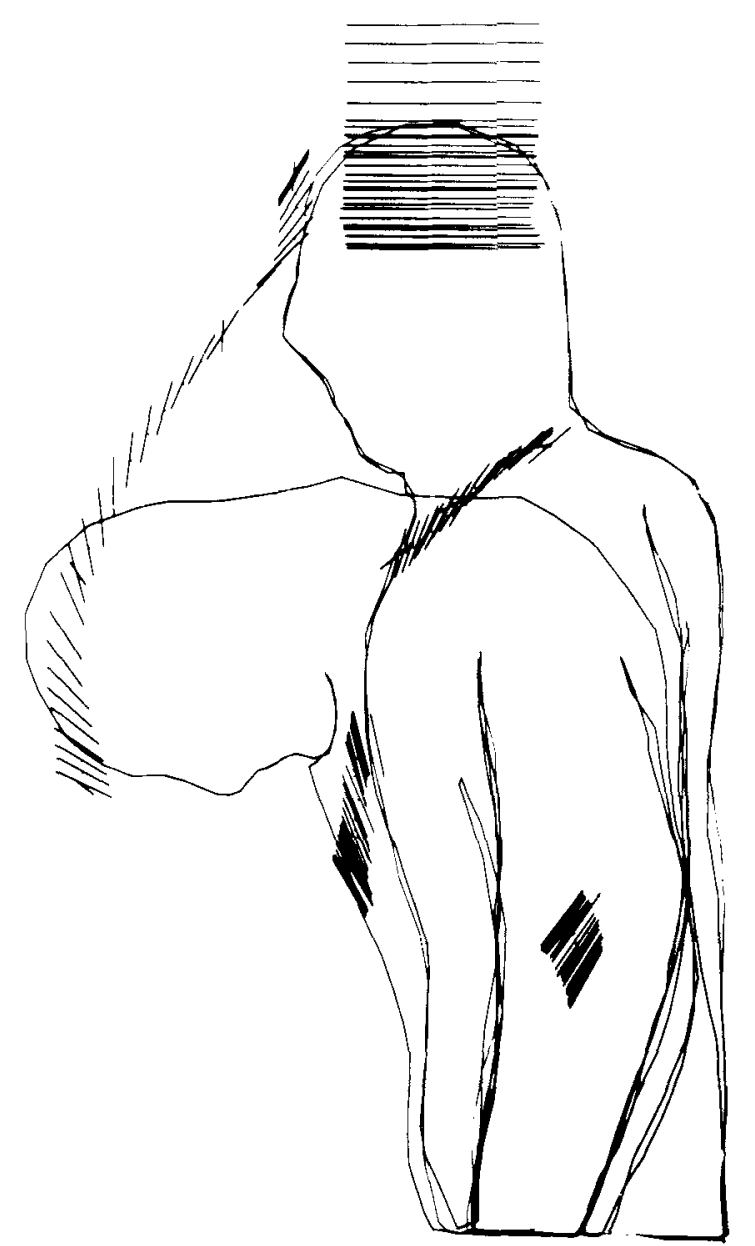

FIG. 5. Film analysis of a cadaver at and immediately postimpact. Vertical lines at right are 3-msec positions of the impactor. Note that the head is driven toward the resistive torso and only late in the sequence does the head go into flexion-after cervical spine damage has occurred.

(a) It appears that "flexion-type" cervical spine damage is unlikely when the head and neck is constrained to move only in the midsagittal plane during crown impact.

(b) Damage may also be found in the upper thoracic spine, with or without cervical spine damage.

(c) When the cervical spine is midsagitally aligned, it may undergo a "serpentine" motion upon impact, resulting in both "extension-type" injury at the C3-C5 level and "flexion-type" injury in the upper thoracic level (T1-T4).

(d) "Flexion-type" damage can routinely be produced with the head/neck/torso is prepositioned to be in a nonmidsagittal plane.

(e) The response of the thoracic spine appears to 

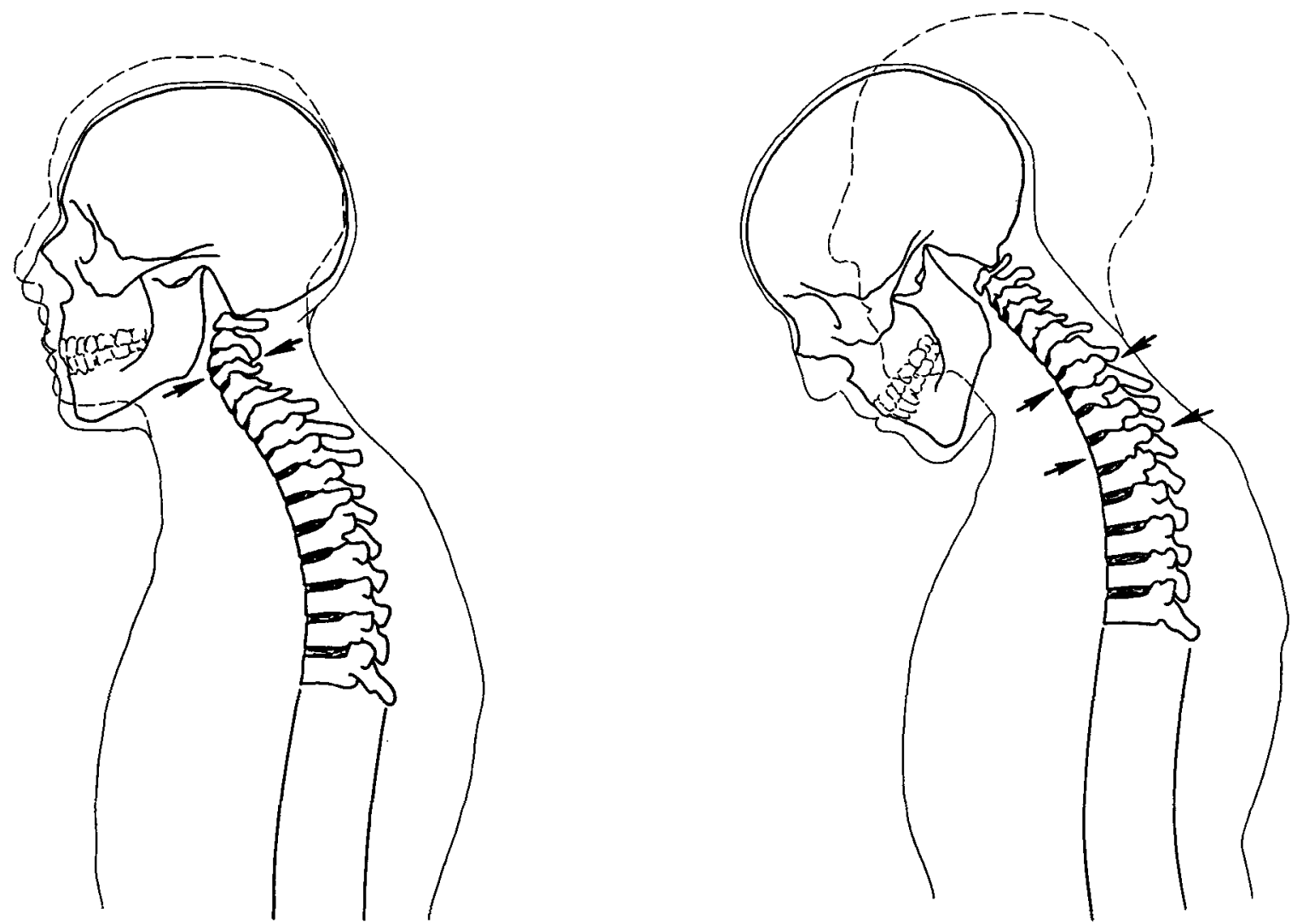

FIG. 6. Typical cervical vertebra position for head flexion (right) and compression motion (left) of about 25 msec after impact. The figure represents artistic reconstruction of high-speed $x$-ray movies taken during impact to the crown of the head. Cervical spine damage, assessed by gross autopsy, occurred at the lower cervical level as well as in the upper thoracic area with the flexion motion impacts. Midsagittal extension or straight compression motion (left) routinely produces upper cervical spine damage.

influence the type of response and the damage patterns produced in the cervical spine. Cervical spine damage is caused by forces from both the head and thorax.

(f) A two-dimensional description of the injury mechanism that is restricted to midsagittal cervical spine-bending (hyperflexion) appears to be inadequate to predict cervical spine damage.

(g) Free-fall cadaver crown impacts do not appear to be significantly different from the $56-\mathrm{kg}$ pendulum impactor tests for similar initial head/neck/torso alignment and impact velocity above $2 \mathrm{~m} / \mathrm{s}$.

Therefore, the possible causes of cervical spine "flexion-type" injury seem to be (a) whipping action of the cadaver head without head impacts in severe deceleration environments $(19,20)$; (b) crown-head impact for a free-falling subject without flexion of the neck or the bowing of the head forward into the thorax $(79,80)$; or (c) a combination of both.

Kallieris et al. (53) determined the loading capacity of human cadaver spines by using an impact sled at 50, 40, and $30 \mathrm{kmph}(31,25$, and $19 \mathrm{mph})$ and various restraint systems. Injury to the spine was located between $\mathrm{C} 1$ and T4. Age was found to be a critical factor in the type of injury produced. King et al. (60) found that the preflexed spine is less tolerant to injury than the more erect spine. Prasad et al. (85) found that the articular facets of the erect spine can be load bearing, increasing the tolerance to vertical impacts.

\section{MATHEMATICAL MODELS}

Mathematical models of the cervical spine have been primarily of the lumped parameter type in which the neck is modeled as a collection of springs, dampers, and masses. Such models are designed primarily to predict motion of the neck to- 
gether with forces and moments, but they do not, without experimental data, give any information about the forces required to cause the various types of neck fractures and fracture/dislocation.

Three basically different types of parameterized neck models have been developed: (a) gross motion models, (b) discrete element models, and (c) databased models.

Gross motion models represent the head, neck, and upper torso as three separate links. The representation of the neck is less detailed than in discrete element models. Compared with discrete element models, gross motion models have the advantages of greater usability of more readily available experimental data (anthropometry, anatomical, materials), less need for estimating values for unknown model parameters, and lessened difficulty in model verification and interpretation of results. Two- and three-dimensional gross motion models are in use.

Discrete element models include, basically, oneto-one representations of structural and soft tissue elements in the neck. The eventual complete development of such models will give them the advantage of being able to be used for predicting stresses and strains in individual elements of the neck. Because of the relative complexity of discrete element models, they have been used mostly for studying two-dimensional motions.

Data-based models are gross motion models, in a sense, but they do not explicitly model viscoelastic or linkage characteristics of the neck, and therefore, cannot be used to investigate dynamic response to arbitrary inputs. Rather, they are best considered as a set of mathematical procedures for analyzing data bases of experimental gross motion response to impact. Data-based models can be used for establishing gross material properties and linkage definition, and further for making limited extrapolations beyond the range of conditions dealt with in the experimental impact testing (normally with human volunteers) represented in the data base.

The gross motion models in greatest use for head/neck simulations are ones developed by Bowman et al. (14), Fleck et al. (27), and Maltha and Wismans (70). Only a three-dimensional model developed by Bowman $(10,13)$ has been used extensively for studying isolated head/neck system dynamics in three dimensions. All of these models have been used in two-dimensional simulations for predicting neck loadings and head response re- sulting from torso and lower body impact excitations. One model, by Bowman et al. (14), has also been used for investigating head/neck dynamics in direct head impacts (12). General findings from use of these models include, as an example, results that imply that muscle contraction may reduce injuries related to head/neck rotational motions in any direction. The models have also been used together with human subject test data to determine values for viscoelastic properties of the neck. Bowman et al. (13) used a three-dimensional model to determine a complete set of lumped parameter values for the neck in three dimensions.

Discrete parameter models include those due to Schultz and Galante $(90)$, Belytschko et al. $(7,8)$, Huston (51), and Goldsmith et al. (34). In two-dimensional simulations, Reber and Goldsmith (86) computed stresses on soft tissue and loads on the vertebrae and determined the areas of most likely damage under particular loading conditions. They found in their simulations that several tissues exceeded a suggested limit of damage substantially and for an extended period of time, pointing to the possibility of serious spinal cord injury.

Data-based "models" include those of Ewing and Thomas $(24,25)$, Ewing et al. (26), Mertz and Patrick (75), Spenny (95), and Wismans and Spenny (106). Human volunteer and cadaver impact response data have been analyzed primarily with the goal of developing improved neck designs for anthropomorphic dummies. Wismans and Spenny (106) have used Naval Biodynamics Laboratory human subject data from frontal and lateral impacts to investigate neck loads near the occipital condyles. The purpose of their investigation was to prescribe dynamic performance requirements for a mechanical analog of the human neck.

Lumped parameter models can be used together with data-based "models" to predict injury. Mertz and Patrick (75) used human volunteer data and human cadaver injury data in order to estimate tolerance levels for the neck. A simple model to study vertex impact was developed by McElhaney et al. (69), and the results were correlated with neck injury data, revealing that torso mass strongly influences neck compression.

Although all three primary types of mathematical models mentioned above have been valuable in studying head/neck dynamics, including prediction of forces and moments in the neck, development work and imaginative application is still needed for all three. Each has been used successfully in in- 
creasing knowledge of neck force levels that can result from impact and that have the potential to cause injury. Each has been used with success in improving our understanding of the mechanisms of head/neck motion. Each type of model has inherent shortcomings, however.

Gross motion models do not model structural and soft tissue elements in the neck on a one-to-one basis, but rather as conceptual elements of a larger scale. These models are therefore inherently limited in how much information they can yield about the impact response of the head and neck. Discrete parameter models impose greater demands for materials data and anatomical data than have been met, and thus, the usefulness of simulation results has been limited. Nor has it been possible yet to verify the behavior of these models adequately on the scale of their individual ("discrete") elements. The primary shortcomings of discrete parameter models stem from their complexity and the improbability of being able to make sufficiently detailed experimental measurements of properties and behavior of the multitude of individual elements in the neck of a living human. It has not yet been possible to make effective use of discrete parameter models in investigation of head/neck responses in three dimensions. Data-based models have two primary limitations. First, as they are only sets of procedures for analyzing head/neck response data, they do not have great value as predictive tools. Second, as they are dependent by definition on experimental data, they are inherently limited by the quality and completeness of the data to be analyzed.

Gross motion, discrete parameter, and databased models have been used together in improving the understanding of the human neck. Because each model has strengths and weaknesses, all will continue to be applied to the study of head/neck impact dynamics. However, application of each type of model is greatly dependent on the availability of good materials data, anatomical data, and dynamic response data, so continued procurement of experimental data is important to the continuing usefulness of head/neck mathematical models.

A potential method of predicting forces necessary to produce injury that was not discussed above is the use of finite element modeling. Finite element models attempt to represent elements or structures as continua, rather than as sets of discrete parameter elements. Thus, in such models, mass, elasticity, and other bulk properties are distributed continuously throughout the model. Finite element models can potentially approximate the anatomy of the neck, as well as its physical properties, better than the discrete parameter models. However, finite element modeling for arbitrary movement has not been accomplished. Only Hosey (40) has developed such a model, and it has not been experimentally verified. A finite element model of the neck for the cervical cord was developed by Ward and reported by Nusholtz et al. (78). Finite element stress analysis of intervertebral discs has been reported by Belytschko et al. (6).

\section{DISCUSSION}

It is not surprising that superior-inferior crown impacts with midsagittal alignment of the head and neck would produce "extension-type" injuries. The normal lordotic curve of the cervical spine predisposes the spine to the extension-type injuries. Only when the head is bent noticeably forward is the cervical column straightened. For years, the classic visual descriptions of gross head movement to cause cervical spine damage (hyperflexion/hyperextension) have not been shown to be necessary to cause the cervical spine damage typically identified with such movements at impact. For experiments in which hyperextension injuries were observed or autopsied, the high-speed films of the impacts indicate the head settling down into the thorax. The initiation of damage to the cervical spine seems to occur for the flexion-type injury early in the impact event, and the noticeable head movement, either forward or backward, occurs later and is probably not associated with the type of injury to the cervical spine. Obvious, but often overlooked, is the fact that most cervical spine injuries and associated damage can be due to the head decelerating on a rigid object with the torso compressing the neck against the occipital condyles. Shallow water diving injury exemplifies this concept.

\section{FUTURE RESEARCH NEEDS}

Thus far, preliminary data on the impact response of the cervical spine as a result of crown impacts are available, primarily in the engineering biomechanics literature. Most of the response data are one- or two-dimensional and represent a limited description of the possible cervical spine, head, and thoracic motions that may occur. 
The indications are that cervical spine injuries are related to three-dimensional kinematics of the head and thorax, as well as to those of the cervical spine. This increased complexity inherent in threedimensional motion makes it difficult, if not impossible, to characterize the mechanism of injury in terms of simple mechanical descriptions limited to a single kinematic parameter, such as peak force or peak velocity. In addition, the inhomogeneous and nonlinear response of the cervical spine make it difficult to characterize the cervical spine response over all impact conditions.

The current technology allows for three-dimensional motion analysis of any rigid body, such as the head or spinal elements, through the use of nine accelerometers and three-dimensional photogrammetry. In addition, high-speed $x$-ray ceneradiography permits in situ viewing of the cervical spine. These methods and techniques, plus the use of strain gages on the cervical spine, enable careful documentation of the necessary parameters for addressing the analysis of the kinematics associated with the impact response and injury mechanism of the cervical spine.

It is recommended that to study the impact response of the cervical spine, a carefully designed test matrix must be developed to address the different types of cervical spine injuries using current state-of-the-art instrumentation. Detailed studies are needed involving the variables of preimpact head, neck, and torso alignment, of impact direction and duration, force, and engineering types of data analyses, including high-speed film digitization for computer analysis.

\section{REFERENCES}

1. Alem NM, Nusholtz GS, Melvin JW: Superior-Inferior Head Impact Tolerance Levels. Final Report. Ann Arbor, University of Michigan Transportation Research Institute, UMTRI-82-41, 1982

2. Alker GJ, Oh YS, Leslie EV, Lehotay J, Panaro VA, Eschner EG: Postmortem radiology of head and neck injuries in fatal traffic accidents. Radiology 114:611-617, 1975

3. Babcock JL: Cervical spine injuries: Diagnosis and classification. Arch Surg 111:646-651, 1976

4. Barnes R: Paraplegia in cervical spine injuries. $J$ Bone Joint Surg 30B:234-244, 1948

5. Bauze, RJ, Ardran GM: Experimental production of forward dislocation in the human cervical spine. $J$ Bone Joint Surg 60B:239-245, 1978

6. Belytschko, T, Kulak RF, Schultz AB: Finite element stress analysis of an intervertebral disc. $J$ Biomech 7:277285,1974

7. Belytschko T, Schwer L, Privitzer E: Theory and application of a three-dimensional model of the human spine. Avi- ation Space and Environmental Medicine 49:1, Sect II, January 1978, pp 158-165

8. Belytschko TB, Privitzer E: Refinement and Validation of a Three-Dimensional Head-Spine Model. Technical Report AMRL-TR-78-7, Wright-Patterson AFB, Ohio, Aerospace Medical Research Laboratory, August 1978

9. Berry J: My Experience as an Executioner, ed by HS Ward, London, Lund and Co, 1892

10. Bowman BM: Analytical Model of a Vehicle Occupant for Use in Crash Simulations. Ph.D. Thesis, University of Michigan, 1971

11. Bowman BM, Robbins DH: Parameter study of biomechanical quantities in analytical neck models. In: 16th Stapp Car Crash Conference Proceedings, New York, Society of Automotive Engineers, 1972, pp 14-44

12. Bowman BM, Schneider LW, Rohr PR, Mohan D: Simulation of head/neck impact responses for helmeted and unhelmeted motorcyclists. In: 25th Stapp Car Crash Conference Proceedings, Warrendale, PA, Society of Automotive Engineers, SAE 811029, 1981 pp 13-68

13. Bowman BM, Schneider LW, Lustick LS, Anderson WR, Thomas DJ: Simulation analysis of head and neck dynamic response. In: 28th Stapp Car Crash Conference Proceedings, Warrendale, PA, Society of Automotive Engineers, SAE 841668, 1984, pp 173-205

14. Bowman BM, Bennett RO, Robbins DH: MVMA Two-Dimensional Crash Victim Simulation, Version 3. Ann Arbor. Final report UMTRI-85-24-1,2,3, June 1985

15. Braakman R, Penning L: Injuries of the Cervical Spine. Amsterdam, Excerpta Medica, 1971

16. Burke DC: Hyperextension injuries of the spine. $J$ Bone Joint Surg 53B:3-12, 1971

17. Burke DC: Spinal cord injuries and seat belts. Med J Aust 2:801-806, 1973

18. Cheng R, Yang KH, Levine RS, King AI, Morgan R: Injuries to the cervical spine caused by a distributed frontal load to the chest. In: 26th Stapp Car Crash Conference Proceedings, Warrendale, PA, Society of Automotive Engineers, 1982, pp 1-40

19. Clemens HJ, Burow K: Experimental investigation on injury mechanism of cervical spine at frontal and rear-front vehicle impacts. In: 16th Stapp Car Crash Conference Proceedings, New York, Society of Automotive Engineers, 1972, pp 76-104

20. Cromack JR, Zipperman HH: Three-point belt induced injuries: A comparison between laboratory surrogates and real-world accident victims. In 19th Stapp Car Crash Conference Proceedings, Warrendale, PA, Society of Automotive Engineers, 1975, pp 1-24

21. Culver RH, Bender M, Melvin JW: Mechanisms, Tolerances and Responses Obtained Under Dynamic-Inferior Head Impact. Final Report. Ann Arbor, University of Michigan, Highway Safety Research Institute, UM-HSRI$78-21,1978$

22. Ewing CL, Thomas DJ, Beeler GW, Patrick LM, Gillis DB: Dynamic response of the head and neck of the living human to $-\mathrm{G}_{\mathrm{x}}$ impact acceleration. In: 12th Stapp Car Crash Conference Proceedings, New York, Society of Automotive Engineers, 1968, pp 424-439

23. Ewing CL, Thomas DJ, Patrick LM, Beeler GW, Small MJ: Living human dynamic response to $-G_{x}$ impact acceleration. II-Acceleration measured on the head and neck. In: 12th Stapp Car Crash Conference Proceedings, New York, Society of Automotive Engineers, 1968, pp 400-415

24. Ewing $C L$, Thomas DJ: Human dynamic response to $-\mathrm{G}_{\mathbf{x}}$ impact acceleration. In: AGARD Conference Proceedings. Paris, AGARD-Cp-88-71, June 1972

25. Ewing CL, Thomas DJ: Torque versus angular displacement response of human head to $-G_{x}$ impact acceleration. 
In: 17th Stapp Car Crash Conference Proceedings, New York, Society of Automotive Engineers, 1973, pp 309-342

26. Ewing CL, Thomas DJ, Lustick L, Muzzy WH, Willems GC, Majewski P: Dynamic response of the human head and neck to $+\mathrm{G}_{\mathrm{y}}$ impact acceleration. In: 21st Stapp Car Crash Conference Proceedings, Warrendale, PA 1977 , SAE 770928

27. Fleck JT, Butler FE, Vogel SL: An Improved Three Dimensional Computer Simulation of Motor Vehicle Crash Victims. Washington, D.C., NHTSA report nos. DOT-HS$801-507$ to 510, NTIS Nos PB-241692,3,4,5, April 1975

28. Fielding JW, Cochran GVB, Lawsing JF, Hohl M: Tears of the transverse ligament of the atlas: A clinical and biomechanical study. J Bone Joint Surg 56A:1683-1691, 1974

29. Forsyth HF: Extension injuries of the cervical spine. $J$ Bone Joint Surg 46A:1792-1797, 1964

30. Foust DR, Chaffin DB, Snyder RG, Baum JK: Cervical range of motion and dynamic response and strength of cervical muscles. In 17th Stapp Car Crash Conference Proceedings, New York, Society of Automotive Engineers, 1973, pp 285-308

31. Frankel V, Burstein A: Orthopedics Biomechanics, the Application of Engineering to the Musclo-Skeletal System. Philadelphia, Lea \& Febiger, 1979

32. Gadd CW, Culver CC, Nahum AM: Study of responses and tolerance of the neck. In: 15th Stapp Car Crash Conference, New York, Society of Automotive Engineers, 1971, pp 256-268

33. Goldsmith W: Some aspects of head and neck injury and protection. In: Progress in Biomechanics, ed by N Akkas, The Netherlands, Sijthoff and Noordhoff, 1979, pp 333-337

34. Goldsmith W, Deng YC, Merrill TH: Numerical Evaluation of the Three-Dimensional Response of a Human HeadNeck Model to Dynamic Loading. Mathematical Simulation of Occupant and Vehicle Kinematics. Warrendale, Pennsylvania SAE 840861, May 1984, pp 79-95

35. Got C, Patel A, Rayon A, Tarriére C, Walfish G: Results of experimental head impacts on cadavers: The various data obtained and their relations to some measured physical parameters. In: 22nd Stapp Car Crash Conference, Warrendale, PA, Society of Automotive Engineers, 1978, pp $55-100$

36. Harris JH, Edeiken J: Acute cervical spine trauma. Wk Radiol Sci Update 17:1-5, 1976

37. Haughton S: On hanging, considered from a mechanical and physiological point of view. Philos Mag 31:23-24, 1866

38. Highway Safety Research Institute: National Crash Severity Study Codebook: Combined phase. HSRI Accident Data System Codebook No. 80-13. Ann Arbor, University of Michigan, Highway Safety Research Institute, December 1980, pp 9-10

39. Hodgson VR, Thomas LM: Mechanisms of cervical spine injury during impact to the protected head. In 24th Stapp Car Crash Conference Proceedings, Warrendale, PA, Society of Automotive Engineers, 1980, pp 15-42

40. Hosey R, Liu YK: A homemorphic finite element model of the human head and neck. In: Proceedings of the International Conference on Finite Elements in Biomechanics, Tucson, University of Arizona, 1980, pp 829-850

41. Hu AS, Bena SP, Zimmerman RM: Response of belted dummy and cadaver to rear impact. In: 21st Stapp Car Crash Conference Proceedings, Warrendale, PA, Society of Automotive Engineers, 1977, pp 587-626

42. Huelke DF, Marsh JC, DiMento L, Sherman HW, Ballard WJ: Injury causation in rollover accidents. In: 17 th American Association for Automotive Medicine Conference Proceedings, Morton Grove, IL, AAAM, 1973, pp 87-115

43. Huelke DF, Lawson TE, Marsh JC: Injuries, restraints and vehicle factors in rollover car crashes. Acc Anal Prev 9:93-107, 1977

44. Huelke DF, Lawson TE, Scott R, Marsh JC: The Effectiveness of Belt Systems in Frontal and Rollover Crashes. Warrendale, PA, Society of Automotive Engineers, SAE 770148, 1977

45. Huelke DF, Mendelsohn RA, States JD, Melvin JW: Cervical fractures and fracture dislocations sustained without head impact. $J$ Trauma 18:533-538, 1978

46. Huelke DF, Moffatt EA, Mendelsohn RA, Melvin JW: Cervical fractures and fracture dislocations: An overview. In: The Human Neck: Anatomy, Injury Mechanisms and Biomechanics, Warrendale, PA, Society of Automotive Engineers, 1979, pp 9-15

47. Huelke DR, O'Day J, Barhydt WH, Lawson TE, Mendelsohn RE: Cervical Injuries in Automobile Crashes, Ann Arbor, University of Michigan, Highway Safety Research Institute, UM-HSRI-80-40, 1980

48. Huelke DR, O'Day J, Mendelsohn RA: Cervical injuries suffered in automobile crashes. $J$ Neurosurg 54:316-322, 1981

49. Huelke DF, Compton C: Injury frequency and severity in rollover car crashes as related to occupant ejection, contacts and roof damage: An analysis of NCSS data. Acc Anal Prev 15:395-401, 1983

50. Huston J.: A Comprehensive Analysis of Head and Neck Dynamics Arising from Impact and Inertia Forces. Ph.D. Thesis, West Virginia University, 1975

51. Huston RL, Passerello CE: Multibody Dynamics Including Translation between the Bodies-with Application to Head-Neck Systems. Cincinnati, Technical report under Office of Naval Research Contract NO 0014-76-C-0 139, 1978

52. Jones AM, Bena SP, Sweeney ES: Injuries to cadavers resulting from experimental rear impact. $J$ Forensic Sci 23:730-744, 1978

53. Kallieris D, Meister B, Schmidt G: Reactions of the cervical spine during frontal impacts of belt protected cadavers. In: Proceedings of the 2nd International Conference on Biomechanics of Serious Trauma, Bron, France, IRCOBI, 1975, pp 126-142

54. Kallieris D, Mattern R, Schmidt G, Warth D: Kinematic and spinal column injuries in active and passive passenger protection: Results of simulated frontal collisions. In: Proceedings of the 1984 International Conference on Biomechanics of Impact, Bron, France, IRCOBI, 1984, pp 279-295

55. Katten KR: Trauma and No-Trauma of the Cervical Spine. Springfield, IL, Charles C Thomas, 1975

56. Kihlberg JK: Flexion-torsion neck injury in rear impacts. In: Proceedings of the 13th American Association for $\mathrm{Au}$ tomotive Medicine Conference, Morton Grove, IL, AAAM, 1969, pp 1-16

57. Kiesel TM, Freirichs RL, Seljeskog EL: Cervical spine injuries. In: Proceedings of the 13th American Association for Automotive Medicine Conference, Morton Grove, IL, AAAM, 1969, pp 73-81

58. King AI: Survey of the state of the art of human biodynamic response. In: Aircraft Crashworthiness, ed by W Pilkey, R Huston, Charlottesville, University Press of Virginia, 1975, pp 83-120

59. King AI: Tolerance of the neck to indirect impact. Technical Report 9, NO 00014-75-C-1015, Detroit, Wayne State University, Bioengineering Center, 1979

60. King AI, Vulcan AP, Cheng LK: Effects of bending on the vertebral column of the seated human during caudocephalad acceleration. In: Proceedings of the 21st Annual Conference on Engineering in Medicine and Biology, vol 10, Houston, Texas 1968, p 32.3 
61. Kraus JF, Franti CE, Riggins RS, Richards D, Borhani NO: Incidence of Traumatic Spinal Cord Lesions. Presented at the 102nd American Public Health Association Meeting, New Orleans, October 1974

62. Kraus JF, Franti CE, Riggins RS, Richards D, Borhani NO: Survival Among Persons Sustaining Acute Spinal Cord Injury. Presented at the 104th American Public Health Association Meeting, Miami Beach, October 1976

63. Lange EW: Mechanical and physiological response of the human cervical vertebral column to severe impacts applied to the torso. In: Symposium on Biodynamic Models and Their Applications. Wright-Patterson AFB, Ohio, Aerospace Medical Research Laboratory, December 1971, pp $141-167$

64. Langwieder $\mathrm{K}$ : Car crash collision types and passenger injuries in dependency upon car construction (field studies of the German automobile insurance companies). In: 16th Stapp Car Crash Conference Proceedings, New York, Society of Automotive Engineers, 1972, pp 158-291

65. Langwiede K: Passenger injuries in collisions and their relation to general speed scale. In: 17th Stapp Car Crash Conference Proceedings, New York, Society of Automotive Engineers, 1973, pp 1-34

66. Levine RS, Patrick LM, Begeman PC, King AI: Effect of quadriceps function on submarining. In: Proceedings of the 22nd American Association for Automotive Medicine Conference, Morton Grove, IL, 1978, pp 319-329

67. McElhaney J, Snyder RG, States JD, Gabrielson MA: Biomechanical analysis of swimming pool neck injuries. In: The Human Neck: Anatomy, Injury Mechanisms and Biomechanics. Warrendale, PA, Society of Automotive Engineers, 1979 , pp 47-53

68. McElhaney JH, Paver JG, McCrackin HJ, Maxwell GM: Cervical spine compression responses. In: 27th Stapp Car Crash Conference Proceedings, Warrendale, PA, Society of Automotive Engineers, 1983, pp 163-178

69. McElhaney JH, Roberts V, Paver J, Maxwell M: Etiology of trauma to the cervical spine. In: Impact Injury of the Head and Spine, ed by C Ewing, D Thomas, A Sances, S Larson, Springfield, IL, Charles C Thomas, 1983, pp 41-71

70. Maltha J, Wismans J: MADYMO-Crash victim simulations, a computerized research and design tool. In: Proceedings of the 5th International Conference on the Biomechanics of Impacts, Bron, France, 1980, pp 1-13

71. Marar BC: Hyperextension injuries of the cervical spine. $J$ Bone Joint Surg 56A:1655-1662, 1974

72. Melvin JW, Mohan D, Stalnaker RL: Occupant Injury Assessment Criteria. Warrendale, PA, Society of Automotive Engineers, SAE 750 914, 1975

73. Melvin JW, Mohan D, Stalnaker RL: Occupant injury mechanisms and impact tolerance. Transport Res Rec 587:11-22, 1976

74. Melvin JW: Human neck injury tolerance. In: The Human Neck: Anatomy, Injury, Mechanisms and Biomechanics. Warrendale, PA, Society of Automotive Engineers, 1979, pp 45-46

75. Mertz HJ, Patrick LM: Strength and response of the human neck. In: 15th Stapp Car Crash Conference Proceedings, New York, Society of Automotive Engineers, 1971, pp 207-255

76. Mertz HJ: Neck injury. In: Biomechanics and Its Application to Automotive Design, New York, Society of Automotive Engineers, January 1973, pp 1-29

77. Moffatt EA, Siegal AW, Huelke DF, Nahum AM: The biomechanics of automotive cervical fractures. In: Proceedings of the 22nd American Association for Automotive Medicine Conference, Morton Grove, IL, AAAM, 1978, pp 151-168
78. Nusholtz GS, Axelrod J, Melvin JW, Ward C: Comparison of Epidural Pressure in Live Anesthetized and PostMortem Primates. Ann Arbor, University of Michigan, Highway Safety Research Institute, HSRI-79-90, 1979

79. Nusholtz GS, Melvin JW, Huelke DF, Alem NM, Blank JG: Response of the cervical spine to superior-inferior head impact. In: 25th Stapp Car Crash Conference Proceedings, Warrendale, PA, Society of Automotive Engineers, 1981, pp 197-237

80. Nusholtz GS, Huelke DF, Lux P, Alem NM, Montalvo F: Cervical spine injury mechanisms. In: 27th Stapp Car Crash Conference Proceedings, Warrendale, PA, Society of Automotive Engineers, 1983, pp 179-198

81. Panjabi MM, White AA III, Johnson RM: Cervical spine mechanics as a function of transection of components. $J$ Biomech 8:327-336, 1975

82. Patrick LM, Levine RS: Injury to the unembalmed belted cadavers in simulated collisions. In: 19th Stapp Car Crash Conference Proceedings, Warrendale, PA, Society of Automotive Engineers, 1975, pp 79-115

83. Pontius UR, Liu YK: Neuromuscular cervical spine model for whiplash. In: Mathematical Modelling Biodynamic Response to Impact, Warrendale, PA, Society of Automotive Engineers, SAE 760770, 1976, pp 21-30

84. Portnoy HE, McElhaney JH, Melvin JW, Croissant PP: Mechanism of cervical spine injury in auto accidents. In: Proceedings of the 15th American Association for Automotive Medicine, Morton Grove, IL, AAAM, 1972, pp $58-83$

85. Prasad P, King AI, Ewing CL: The role of the articular facets during $+\mathrm{G}_{2}$ acceleration. $J$ Appl Mech 41:321-326, 1974

86. Reber JB, Goldsmith W: Analysis of large head/neck actions. J Biomech 12:211-222, 1979

87. Sances A, Myklebust JB, Mhiman DJ, Larson SJ, Cusick JF, Jodat RW: The biomechanics of spinal injuries. CRC Crit Rev Biomed Eng 11:1-76, 1984

88. Schneider R: Head and Neck Injuries in Football: Mechanisms, Treatment, and Prevention. Baltimore, Williams \& Wilkins, 1973

89. Schneider LW, Foust DR, Bowman BM, Snyder RG, Chaffin DB, Abdelnour TA, Baum JK: Biomechanical properties of the human neck in lateral flexion. In: 19th Stapp Car Crash Conference Proceedings, Warrendale, PA, Society of Automotive Engineers, 1975, pp 455-485

90. Schultz AB, Galante JO: A mathematical model for the study of the mechanics of the human vertebral column. $J$ Biomech 3:405-416, 1970

91. Selecki BR: Cervical spine and cord injuries: Mechanisms and surgical implications. Med $J$ Aust 1:838-840, 1970

92. Synder RG: Human Impact Tolerance: State of the Art. New York, Society of Automotive Engineers, SAE 700398, 1970

93. Snyder RG, Chaffin DB, Schneider LW, Foust DR, Bowman BM, Abdelnour TA, Baum JK: Basic Biomechanical Properties of the Human Neck Related to Lateral Hyperflexion Injury. Ann Arbor, University of Michigan, Highway Safety Research Institute, UM-HSRI-75-5, 1975

94. Spence DF, Becker S, Sell KW: Bursting alantal fracture associated with rupture of the transverse ligament. $J$ Bone Joint Surg 52A:543-549, 1970

95. Spenny CH: Analysis of Head Response to Torso Acceleration, NHTSA Technical Report, Cambridge, MA, Transportation Systems Center, December 1984

96. States KD, Korn MW, Massengil JM: The enigma of whiplash. NY State J Med 70:2971-2978, 1970

97. Suh $\mathrm{CH}$ : Dynamic simulation of the cervical spine with use of differential displacement matrix. In: Proceedings of the 
3rd International Conference on Impact Trauma, Bron, France, IRCOBI, 1977, pp 355-365

98. Taylor AR: The mechanism of injury to the spinal cord in the neck without damage to the vertebral column. J Bone Joint Surg 33B:543, 1951

99. Taylor AR, Blackwood W: Paraplegia in hyperextension cervical injuries with normal radiographic appearances. $J$ Bone Joint Surg 30B:245-248, 1948

100. Torg J: Athletic Injuries to the Head, Neck, and Face. Philadelphia, Lea \& Febiger, 1982

101. Torg J, Truex R, Marshall J, Hodgson VR, Quedenfeld TC, Spealman AD, Nichols CE: Spinal injury at the level of the third and fourth cervical vertebra from football. $I$ Bone Joint Surg 59A:1015-1019, 1977

102. Torg J, Quedenfeld T, Burstein A, Spealman AD, Nichols
CE: National football head and neck injury registry: Report on cervical quadriplegia, 1971 to 1975. Am J Sports Med 7:127-132, 1979

103. Van Eck PJ, Chaffin DB, Foust DR, Baum JK, Synder RG: A Bibliography of Whiplash and Cervical Kinematic Measurement. Ann Arbor, University of Michigan, Highway Safety Research Institute, UM-HSRI-BI-73-6, 1973

104. Watts DT, Mendelson ES, Hunter HN, Kornfield AT, Poppen JR: Tolerance to vertical acceleration required for seat ejection. J Aviation Med 18:554, 1947

105. Whitley JE, Forsyth HF: The classification of cervical spine injuries. Am J Roentgenol 83:633-644, 1960

106. Wismans J, Spenny CH: Head-neck response in frontal flexion. In: 28th Stapp Car Crash Conference Proceedings, Warrendale, PA, 1984, SAE 841666, pp 161-172 